\title{
The Value Sublimation of Study Tour Based on the Background of the New Era
}

\author{
Yao Liyan ${ }^{1, a}$, , Shi Mengqi ${ }^{2, b}$,Fang Jiajue ${ }^{3, c, *}$ \\ ${ }^{1}$ School of Culture and Communication of Guangxi Science \& Technology Normal University; Laibin, Guangxi, China \\ 546199 \\ ${ }^{2}$ Student Affairs Office of Guangxi Science \& Technology Normal University; Laibin, Guangxi, China 546199 \\ ${ }^{3}$ Teaching Quality Monitoring and Evaluation Office of Guangxi Science \& Technology Normal University; Laibin, \\ Guangxi, China 546199 \\ 15878434051@163.com \\ b404284591@qq.com \\ cJiayu10000@163.com
}

\begin{abstract}
Under the background of the new era, the study tour is a new type of open course, which is guided and encouraged by the research institutions and tutors. The aim is to encourage the young students to learn and practice, and to meet the needs that seeking knowledge. In the modern context, we should give full play to the power of big data, encourage the integration of practice and skill learning of students, and transform the research practice into the national spirit with patriotism as the core and the spirit of the times with reform and innovation as the core. Under the background of the new era, study tour consciously transforms meeting students' demand for knowledge into developing and promoting students' patriotism and practical innovation, strengthening the expression and interpretation of students' internal drive, and other core qualities as the goal of research and study value, which is different from the traditional teaching mode of research and study.
\end{abstract}

Keywords: new era, study tour, value sublimation

\section{基于新时代背景下研学旅行的价值升华 \\ 姚丽妍 ${ }^{1, a}$, 石梦琪 ${ }^{2, b}$, 方家理}

${ }^{1}$ 广西科技师范学院文化与传播学院; 来宾, 广西, 中国 546199

2 广西科技师范学院学生工作处; 来宾, 广西, 中国 546199

3 广西科技师范学院教学质量监控与评估处; 来宾, 广西, 中国 546199

15878434051@163.com

b404284591@qq.com

cJiayu10000@163.com

摘要：新时代背景下的研学旅行是由研学机构、研学导师等引导和鼓励青少年学生学习、实践, 满足青少年 学生求知需求的一种新型开放式课程。在现代背景下充分发挥大数据能量,鼓励学生实践与技能学习融合发展, 将研学实践活动转化为具有以爱国主义为核心的民族精神和以改革创新为核心的时代精神等核心素养。新时代 背景下的研学旅行有意识的将满足学生求知需求转换为培养和提升学生爱国主义精神与实践创新、加强学生内 驱力的表达与诠释等核心素养为研学价值目标并区别于传统研学求知形态的教学方式。

关键词：新时代；研学旅行；价值升华

\section{1.前言}

在科技革命、市场经济发展等客观因素条件下, 中国开创了新时代纪元, 同时也推动了社会主义文化
发展, 当今社会是大数据高速发展时代, 经济决定文 化, 文化反作用于经济, 并为经济发展提供动力支持。 社会文化发展基于经济发展, 在大数据发展的创新课 程改革背景下, 研学旅行加强了学生核心素养的培育, 并在提高经济效益的同时推动社会效益的发展, 应验 
了“经济进步同私有制、经济自由原则和个人主义意 识这种文化上历史上的联系” ${ }^{[1]}$ 。新时代背景下的我 们要将爱国主义精神转化成人们的情感认同, 加强中 华优秀传统文化继承性、创新性、转化型发展, 培养 青少年学生爱国主义精神, 继承革命文化, 积极引导 和鼓励其时代创新思维, 激发青少年基于时代精神下 的创新能力和实践能力, 加强社会主义精神文明建设, 使爱国主义精神融入社会发展的各个方面。[2]本文基 于当代网络大数据迅速发展和新课程改革背景, 探究 本篇论文所提出的研学旅游课程的实施背景和价值, 结合培养和提升学生核心素养进行本文的论述和探 讨。

\section{2.新时代研学旅行背景}

\section{1 研学旅行的发展优势}

研学旅行提倡实地实践, 以此满足求知需求, 是 一种新型教育方式, 在时代快速发展下, 研学教育不 局限于校内快餐式教育, 倡导实践为理论提供基础, 在研学实践中发挥意识形态作用, 有效引导学生传承 爱国主义精神与时代精神, 是当前社会下教育方式的 一大创新。研学旅行作为一种以研学实践为基础的新 型教育方式, 能为学生学习理论知识与科学素养奠定 良好基础, 能够体现现今中国特色社会主义理论中倡 导的爱国主义与时代精神相结合的科学性, 这也是一 种新型的开放式教育的体现, 它不拘泥于校内学习, 而是在校外各个研学基地进行实地学习实践, 让学生 走进历史, 观照人民生活, 反映人民创造, 表达人民 心声，并对此进行自我学习教育反哺。

在此基础上, 政府出台了一系列文件和意见对研 学旅行发展提供政策支持和保障。教育部等 11 个部 门联合颁发的《关于推进中小学生研学旅行的意见》 提出要求加强研学旅行基地的建设, 于 2017 年、 2018 年公布了全国中小学生首批研学实践教育基地和营 地名单, 这些政策的出台为研学旅行发展提供支持和 可行性探究, 为研学旅行发展提供可行性方案。[3]]

\section{2 研学旅行的障碍制约}

基于目前国内教育大环境背景, 教学教育方式还 是以学校为主导, 教师为主体, 而研学旅行教育将学 生作为主体, 将研学机构和研学导师作为引导。但是 新型的研学旅行教育方式存在一些发展障碍, 如重游 轻学、规划随意、组织实施“去学生化”、评价单一等 问题 ${ }^{[4]}$, 也存在着研学安全出行问题、学生实际学习 问题、学生实践创新问题、研学形式主义问题、研学 导师引而不教等问题。多数家长、机构等顾及学生研 学实践出行和知识汲取方面的问题, 是当前研学发展 受到制约的关键因素, 这需要我们对研学旅行行业保 持清醒状态, 精准识别研学旅行行业发展痛点并弥补 关键短板, 才能有效推动研学旅行健康发展。

\section{3.研学旅行的学生主体作用}

\section{1 学生主体作用: 学会学习与实践创新}

现阶段的学校教育还是以教师为主导, 学生作为 被接受的一方进行传输式的系统性学习, 在学习过程 中较多的受到教师教育的支配感, 其对学习的方式、 内容、过程有着较少的自主支配权, 且求知需求的各 方面的选择性也较小。但是研学旅行突出学生的主体 性, 研学导师和机构起到一种引导性作用, 为学生服 务突出学生主体, 有利于加强学生自主学习和实践创 新的动力, 培养学生知识学习的专门化和自主学习的 主观能动性, 加强学生对各类知识的渴望, 正确把握 其意识形态作用。研学旅行针对各个研学基地开发出 各类课程, 其对各类课程的设置与实地应用考察, 不 仅能培养学生形成一定的实践意识, 还能有效培养学 生的核心素养, 研学旅行通过发挥实践课程的生动性 与多样性, 丰富学生精神文化生活, 提高学生科学文 化素质和身心健康素质, 从而使学生以更加积极乐观 的心态投入到学习活动之中。[5]

学生是受教育的主要人群, 也是学习的主体, 他 们不仅是历史传承的重要因素, 还是文化内涵的传播 者。对于研学基地的选取和展现昭示着其背后的传达 内容和精神内核, 而学生作为研学学习主体学习研学 基地背后的内容和精神, 有利于学生主动适应和融入 社会, 促使书本知识和生活实践能力的深度融合, 有 利于加强其实践能力和历史文化的表达，对构建历史 文化价值和传承民族精神血脉具有重要作用。

\section{2 研学机构及导师引导作用加强主体培养}

当代社会下的研学机构及导师属于一种物质层 面的引导符号性内容, 研学机构和研学导师是当代研 学旅行活动的开展者、实施者, 其具备倡导主流意识 的倾向, 其思想态度、价值观与意识形态等应与国家 相统一, 这要求研学导师应具有健康的身体状况和丰 富的专业知识为指导基础、优良的道德素养为模范榜 样, 拥有良好的抗压应变和适应能力等为特定的工作 环境和特点进行教育行为, 加强学生主体主观能动性 的培养, 使其在研学学习过程中充分发挥学生学习主 体功能, 使得学生在学习过程中不断得到自我反馈, 引导学生在思想态度、价值观与意义以及这些在物质 和行为形态上的行为与实践的具体化。[6]

研学机构及研学导师作为一种引导性学习的行 为具体实践的产物, 能够真实反映研学问题, 落实研 学课程开发与设计, 着眼于学生实践知识能力培养和 历史文化传播, 通过广泛连接各类协作主体 (如学校、 教育局、旅行社等) 和研学资源进行教育方式创新, 引导学生主动参与实地研学, 实现更高效的历史文化 传承, 构建学生主体学习模式, 打破传统教育教学方 式壁垒, 以学生为主体方向, 创新挖掘学生实践能力, 培养其正确的学习态度和价值观念, 系统构建研学基 地的历史文化价值。 


\section{4.研学价值由满足学生求知需求逐渐转为培 养学生核心素养的升华}

\section{1 研学旅行的初始功能: 求知需求需要、教 育方式创新}

在互联网技术快速发展、教育载体多样化、社会 生活碎片化的背景下, 研学旅行作为一种新型教育方 式逐渐兴起, 它是对传统教育方式的一种发展和创新, 使得历史通过留存遗址等作为符号进行有效记录和 传承爱国精神、中国精神等。研学旅行充分利用研学 基地在中国历史发展中对中国文明和中国精神的推 进作用和传承作用进行开发和设计, 满足学生求知需 求, 创新传统学校教育方式, 使其不仅单从书本上获 得知识, 而且让学生更加直观的了解人民创造能力、 历史传统和时代精神, 更容易把握中华文明和民族精 神以及历史上中国人的智慧之美。开展研学旅行, 不 仅满足了学生的求知需求, 更有利于促进学生培育核 心素养, 激发学生对国家和人民的热爱; 有利于创新 教育教学方式, 推动全面实施素质教育, 创新人才培 养模式, 引导和培养学生社会责任和国家认同感 ${ }^{[7]}$ 。

\section{2 现代社会与客观环境的匹配}

新时代背景下, 现代大众传媒急速发展, 体现了 以往任何一种传播媒介都无法比拟的强大威力和传 播优势, 基于交互式新媒体和移动通讯等出现的情况 下贯彻新发展理念, 现代研学开创了一些线上线下结 合的课程, 开创了一种新式教育教学的发展格局, 使 得研学这种新型的教学方式更加形象直接地向人民 大众普及。我们面临着文化多元化、文化复古化、信 息网络化等浪潮的影响和冲击, 在经历利益格局的深 刻调整、社会结构的重大变化、思想观念转变等情况 下, 现代研学旅行作为一种新时代下的新型开放式教 育给了我们更加直观鲜活的体验, 通过视觉等感官体 验挖掘历史, 使得中华五千年文明的精华有一种跨历 史的穿透力, 让学生的实践创新能力得到更大优势的 发展, 更容易弘扬爱国主义和时代精神, 中国特色社 会主义文化可以进一步繁荣发展, 加强新一代青年的 中国精神的培养, 使学生树立正确的价值观和世界观, 逐渐树立起大国文化形象 ${ }^{[8]}$ 。

2019 年, 习近平总书记在参加全国政协第十三 届二次会议文化艺术界、社会科学界委员联组会时指 出, 希望大家立足中国现实, 根植中国大地, 把当代 中国发展进步和当代中国人精彩生活表现好展示好, 把中国精神、中国价值、中国力量阐释好 ${ }^{[9]}$ 。而研学 旅行则是基于中国现实, 将中国发展历史进行课程设 计的展现, 当代青年基于时代发展精神培育的基础上 着重培养学生爱国主义精神, 而爱国主义精神的培育 则着力于爱国主义与改革创新最终以实现中华民族 伟大复兴的中国梦上, 我们应在研学课程设计上坚持 历史传承性与时代发展性、政治性与文化性、理论性 与实践性、民族性与世界性的统一, 利用现代科学技
术, 把握机构政策等客观因素, 加强学生实地研学实 践, 增强当代学生中国精神培育实际效果。

\section{3 教学课程与内容设计的实践功能}

研学旅行作为一种教育方式, 是历史教育传承中 不可或缺的传播载体, 也是对内实现跨历史的文化教 育交流、拓展民族内涵和国家历史的重要方式; 对外 立足国家历史发展进程的高度，深刻洞察民众精神传 承, 倡导构建有历史、有文明、有精神的思想意识。 其目的是整合该地域的历史痕迹，传承爱国主义精神， 激活民众对中国历史的高度认同，唤起国家民族的群 体记忆，培养以爱国主义为核心的民族精神。

其对于该地域的历史发掘, 有利于研学团队进行 探究、实践、体验式的研学课程设计, 并以此有意识 的培养学生构建历史精神的思想意识, 使得学生在进 行研学实践时能够充分把握和了解当地历史动向和 历史发展轨迹, 有意识的培养学生共情能力, 加强其 对中国历史的表达能力和探究能力, 实现当地研学基 地开发的感悟性、体验性、探究性的目的。习近平在 纪念五四运动 100 周年大会中强调: “把青年一代培 养造就成德智体美劳全面发展的社会主义建设者和 接班人, 是事关党和国家前途命运的重大战略任务, 是全党的共同政治责任” [10]。研学旅行作为一种新型 教育教学方式, 能够打破传统教育以教师为主导的教 学方式, 转而以学生为主体, 根据研学基地历史背景 设计课程, 让学生主动参与学习, 激发其探究欲望、 提高其学习积极性, 利用当代各类技术的发展, 以大 跨度的方式向学生展现研学基地历史背景和历史意 义, 推动学生学习自主性, 有利于学生发挥主观能动 性, 加强其民族精神和时代精神的培养, 使得学生青 年成为国家和民族的未来和标向。

\section{4 学生实践性思维诠释和内驱力表达}

当今世界正经历百年未有之大变局, 创新则是其 中一个关键标量。而青少年创新性思维可以以小见大 推动民族创造力的发展, 基于此情况, 我们要充分认 识推动教育发展的重要性和紧迫性, 于危机中孕育先 机、于变局中开创新局, 把握时代发展大趋势, 下好 先手棋, 加强学生在新型教育方式下的民族精神和创 新思维的培养, 主动把握时代青年发展标向, 引导其 正确诠释实践性思维和创新发展的内驱力表达, 加强 其爱国主义精神和民族认同感。

《新纲要》明确规定“新时代爱国主义教育要面 向全体人民、聚焦青少年”，坚持“把青少年作为爱国 主义教育的重中之重” [11]。国家和民族的发展需要精 神力量的支持, 青年是一个国家和民族的未来, 其肩 负着重要的社会责任, 当前社会下为实现中华民族伟 大复兴更需要培养我们青年一代的民族精神和时代 精神, 凝聚民族精神和民族品格。习总书记强调, 我 们应将思想政治工作贯穿教育教学全过程, 根据大数 据时代的不断发展, 我们更应该注重学生思想品德的 
教育，在知识传授中强调当代社会价值观的同频共振， 其中我们应该加强培养学生以爱国主义为核心的民 族精神和以改革创新为核心的时代精神。研学旅行注 重实地考究研学, 并在此基础上深入开展国情教育, 广泛组织开展研学实践活动 ${ }^{[12]}$ 。在当前社会下, 研学 旅行通过研学基地的历史经历开发相应的研学课程 等, 着重响应当前以爱国主义为核心的革命精神和时 代精神, 倡导主旋律, 有意识地培养学生历史认同感、 国家认同感等, 加强培养以爱国主义为核心的民族精 神和以改革创新为核心的时代精神, 以此更好地了解 国情民情, 强化社会责任和历史担当, 最终实现民族 精神和时代精神的统一, 即继承和发扬中国精神。

\section{5.结论}

研学旅行以实地实践学习为基础, 引导学生主动 参与, 利用现代科技力量以大跨度的方式充分还原历 史发展背景, 研学基地课程设计从历史发展出发到历 史变革中蕴含的情感、习俗、智慧和文化等, 准确把 握历史内涵、民族精神和时代精神, 以研学实践唤起 学生的家国情怀和民族认同, 有意识地将满足学生求 知需求转换为培养和提升学生爱国主义精神与实践 创新、加强学生内驱力的表达与诠释等核心素养为研 学价值目标。

\section{项目基金}

本文为 2020 年国家级大学生创新训练计 划项目《桂中中小学爱国主义研学旅行的研究 与实践》（项目编号 202011546009）的阶段性 研究成果之一

\section{REFERENCES}

[1] Lenin's Complete Works: Volume One [M]. Beijing: People's Publishing House, 1984: 595.

[2] Yang Jingyun. The four dimensions of a powerful socialist country $[\mathrm{N}]$. China Social Science News Central level 2020-11-27(8) .

[3] Lao Yinji, Lin Xiaobiao, Wu Shidai. Analysis of the spatial pattern and development influencing factors of national research bases [J]. Journal of Fujian Normal University ( Natural Science Edition), 2021,27: (02): 87-98.

[4] Yu Shujuan, Wang Yuan, Wu Huijun. The Causes and Countermeasures of the Problem of Research and Study Travel in my country [J]. Journal of Teaching and Management,2017(19):11-13.

[5] You Huishuan. An Analysis of the Value and Implementation Strategy of Research and Study Travel in the Course of Comprehensive Practical Activities [J]. Elite Teachers Online , 2021
(07):49-50 .

[6] Li Xianyue Zhang Liping. Discussion on the Quality and Ability of Compound Research Tutors [J]. Journal of Heihe University, 2021， 12(01): 90-92.

[7] Mao Yao. Cultivation of the Chinese Spirit of College Students in the New Era. Journal of Southwest Jiaotong University [J]. Social Science Edition, 2021 (02): 10-17.

[8] 11 departments including the Ministry of Education. Opinions on the promotion of research trips for elementary and middle school students $[\mathrm{EB} / \mathrm{OL}]$.: (2016-12-19)

[2021-4-24] http://www.gov.cn/xinwen/2016-12/19/content_514 9947.htm

[9] Xi Jinping visits the members of the cultural and social science circles participating in the CPPCC meeting - Xinhuanet [EB/OL].: (2019-03-04) [2021-4-24] http://www.xinhuanet.com/politics/2019lh/2019-03 /04/c_1124192099.htm

[10] Xi Jinping. Speech at the General Assembly Commemorating the 100th Anniversary of the May Fourth Movement ( 2019-4-30 ) [N]. People's Daily,2019-05-01（2）.

[11] Bai Yunhua. Several Important Provisions on the Patriotic Education of Young People in the New Era_-Based on the Analysis of the "Outline for the Implementation of Patriotism Education in the New Era" [J]. The Party Building and Ideological Education in Schools,2019(19):42-46.

[12] "Outline for the Implementation of Patriotic Education in the New Era" issued by the Central Committee of the Communist Party of China and the State Council [EB/OL].: (2019-11-12) [2021-4-24] http://www.gov.cn/zhengce/2019-11/12/content_54 51352.htm 